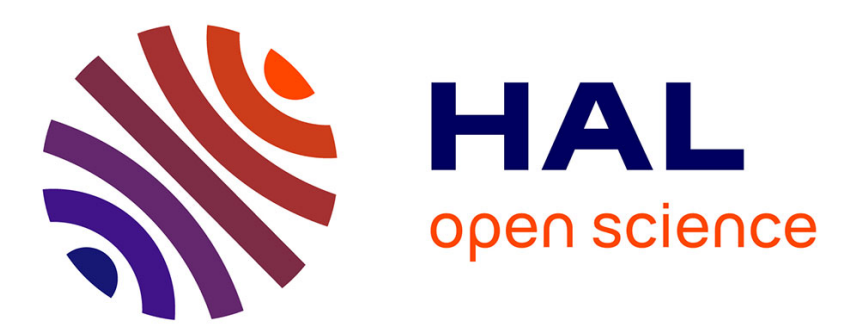

\title{
Thermoelectric Properties of Magnesium-Doped Tetrahedrite Cu12-xMgxSb4S13
}

Petr Levinský, Christophe Candolfi, Anne Dauscher, Bertrand Lenoir, Jiř́ Hejtmánek

\section{> To cite this version:}

Petr Levinský, Christophe Candolfi, Anne Dauscher, Bertrand Lenoir, Jiří Hejtmánek. Thermoelectric Properties of Magnesium-Doped Tetrahedrite Cu12-xMgxSb4S13. Journal of Electronic Materials, 2019, 48 (4), pp.1926-1931. 10.1007/s11664-019-07032-w · hal-02391354

\section{HAL Id: hal-02391354 \\ https://hal.science/hal-02391354}

Submitted on 19 Feb 2020

HAL is a multi-disciplinary open access archive for the deposit and dissemination of scientific research documents, whether they are published or not. The documents may come from teaching and research institutions in France or abroad, or from public or private research centers.
L'archive ouverte pluridisciplinaire HAL, est destinée au dépôt et à la diffusion de documents scientifiques de niveau recherche, publiés ou non, émanant des établissements d'enseignement et de recherche français ou étrangers, des laboratoires publics ou privés. 


\title{
Thermoelectric properties of magnesium-doped tetrahedrite $\mathrm{Cu}_{12-x} \mathrm{Mg}_{x} \mathrm{Sb}_{4} \mathrm{~S}_{13}$
}

P. Levinsky1,2,3,*, C. Candolfi1, A. Dauscher1, B. Lenoir1, J. Hejtmánek2

1 Institut Jean Lamour, UMR 7198 - CNRS - Université de Lorraine, 2 allée André Guinier, 54011 Nancy, France

2 Institute of Physics of the Czech Academy of Sciences, Na Slovance 2, 18221 Prague 8, Czech Republic

3 Faculty of Nuclear Sciences and Physical Engineering, Czech Technical University in Prague, Brehova 7, 11519 Prague 1, Czech Republic *e-mail: levinsky@ fzu.cz, phone: +420 220318483

\begin{abstract}
Tetrahedrites, naturally occurring sulfosalt minerals, have been shown to exhibit peak $Z T$ values close to unity near $700 \mathrm{~K}$ due to the combination of semiconducting-like properties and extremely low lattice thermal conductivity. A wide range of elements can be substituted into tetrahedrites, each of them affecting the thermoelectric properties. Interestingly, all tetrahedrites reported to date contain exclusively $d$ - and $p$-block elements of the periodic table. Here, we demonstrate that magnesium, an s-block element, can be successfully introduced in $\mathrm{Cu}_{12} \mathrm{Sb}_{4} \mathrm{~S}_{13}$. We successfully prepared a series of polycrystalline samples $\mathrm{Cu}_{12}-$ ${ }_{x} \mathrm{Mg}_{x} \mathrm{Sb}_{4} \mathrm{~S}_{13}$ with nominal compositions $x=0.5,1.0,1.5$. Powder $\mathrm{X}$-ray diffraction and chemical mapping confirmed that approximately half of the $\mathrm{Mg}$ atoms were incorporated into the tetrahedrite unit cell, while the other half forms electrically insulating MgS precipitates. Thermoelectric properties, measured between 5 and $673 \mathrm{~K}$, show that the effect of $\mathrm{Mg}_{2+}$ is similar to that of other aliovalent elements substituting for either $\mathrm{Cu}$ or $\mathrm{Sb}$. In particular,
\end{abstract}


increasing the $\mathrm{Mg}$ content drives the system closer to a semiconducting behavior, leading to a concomitant increase in the thermopower and electrical resistivity and a decrease in the electronic part of the thermal conductivity. Because these two trends counterbalance each other, the overall effect of $\mathrm{Mg}$ on the $Z T$ of $\mathrm{Cu}_{12} \mathrm{Sb}_{4} \mathrm{~S}_{13}$ is found to be marginal with a peak $Z T$ of 0.55 at $673 \mathrm{~K}$.

\section{Keywords}

Thermoelectric; Tetrahedrite; Magnesium substitution; Material synthesis

\section{Introduction}

Thermoelectric (TE) materials allow direct, solid-state conversion between heat and electricity. The efficiency with which heat is converted into electricity and vice-versa is directly related to the dimensionless thermoelectric figure of merit $Z T=S_{2} T /(\rho \kappa)$, where $T$ is the absolute temperature, $S$ is the Seebeck coefficient or thermopower, $\rho$ is the electrical resistivity and $\kappa$ is the total the thermal conductivity. [1,2] Tetrahedrites, a family of compounds based on an eponymous sulfosalt mineral that can be mined worldwide, have recently been found to possess favorable thermoelectric properties. [3] Tetrahedrites can be described by the general chemical composition $\mathrm{Cu} 10(\mathrm{Zn}, \mathrm{Fe}, \mathrm{Cu}, \ldots) 2(\mathrm{Sb}, \mathrm{As}) 4 \mathrm{~S}_{13}$ which is a multicomponent variant of the ternary tetrahedrite $\mathrm{Cu}_{12} \mathrm{Sb}_{4} \mathrm{~S}_{13}$. [4]

While naturally occurring tetrahedrite minerals are not directly suitable for TE applications because of their nearly intrinsic semiconducting electrical properties synonymous with high electrical resistivity values, [5] synthetic tetrahedrites with optimized chemical composition have been shown to reach peak $Z T$ values close to unity near $700 \mathrm{~K} .[6,7,8]$ Such good thermoelectric performance is mainly due to their extremely low lattice thermal conductivity with values as low as $0.5 \mathrm{~W} \mathrm{m-1} \mathrm{K-1} \mathrm{at} 700 \mathrm{~K}$. [9] These low values along with 
the glass-like temperature dependence have been shown to originate from strongly anharmonic, low-energy optical modes associated with unconventional thermal vibrations of some of the $\mathrm{Cu}$ atoms. $[10,11,12]$ Partial substitutions by transition metals or chalcogenides on the $\mathrm{Cu}, \mathrm{Sb}$ or $\mathrm{S}$ sites help to drive the metallic properties of $\mathrm{Cu}_{12} \mathrm{Sb}_{4} \mathrm{~S}_{13}$ towards a heavilydoped semiconducting state more favorable for thermoelectric performance. In this context, a wide range of elements have been considered with the aim of determining their influence on the thermoelectric properties of $\mathrm{Cu}_{12} \mathrm{Sb}_{4} \mathrm{~S}_{13}$. These substitutions include $\mathrm{Se}[13,14]$ on the $\mathrm{S}$ site, As [15], Te [16, 17] and $\mathrm{Bi}[18]$ on the Sb site, and a dozen of different elements on the $\mathrm{Cu}$ site such as Fe [6], Co [7], Ni [19, 20], Zn [6], Cd [21] or Sn [22]. Several elements can be substituted simultaneously. [4, 23, 24, 25, 26, 27, 28]

Nevertheless, all tetrahedrites reported to date contain exclusively $d$ - and $p$-block elements of the periodic table. Here, we demonstrate for the first time that $\mathrm{Mg}$, an $s$-block element, can be successfully substituted for $\mathrm{Cu}$ in $\mathrm{Cu}_{12} \mathrm{Sb}_{4} \mathrm{~S}_{13}$. We present analyses performed by powder X-ray diffraction and scanning electron microscopy and transport property measurements carried out over a wide range of temperatures.

\section{Experimental Details}

Polycrystalline samples of $\mathrm{Cu}_{12-x} \mathrm{Mg}_{x} \mathrm{Sb}_{4} \mathrm{~S}_{13}$ were prepared via powder metallurgy. Pure elements (Cu powder 99.95\%, Mg powder 99.99\%, Sb shots $99.999 \%$, S pieces $99.999 \%)$ were mixed in stoichiometric quantities in an Ar-filled glove box and sealed in evacuated silica tubes under secondary vacuum. These tubes were placed in a rocking furnace and heated at $670{ }^{\circ} \mathrm{C}$ for $12 \mathrm{~h}$ with slow warming and cooling rates $(0.3 \mathrm{~K} \mathrm{~min}-1$ and $0.5 \mathrm{~K} \mathrm{~min}-1$, respectively) because of the high vapor pressure of sulfur. Resulting ingots were crushed and cold pressed into cylindrical pellets which were sealed under secondary vacuum in silica tubes. Subsequent annealing at $450{ }^{\circ} \mathrm{C}$ for 5 days was completed by quenching the tubes in 
cold water. The pellets were ground into fine powders which were consolidated by spark plasma sintering (SPS) at $80 \mathrm{MPa}$ for $4 \mathrm{~min}$ at $450{ }^{\circ} \mathrm{C}$ using the SPS Syntex Dr Sinter 515 apparatus. The consolidated pellets had a relative density ranging between $95 \%$ and $98 \%$ of the theoretical density, the sample with the lowest $\mathrm{Mg}$ content being the densest.

Crystal structure and phase purity were investigated by powder X-ray diffraction (PXRD) at $300 \mathrm{~K}$ using a Bruker D8 Advance diffractometer (Cu Ka1 radiation). Rietveld refinements were performed using the FullProf Software [29] to determine the lattice parameters of the samples and to estimate the fraction of secondary phases. An FEI Quanta 650 FEG scanning electron microscope (SEM) was used to study the sample morphology by back-scattered electron (BSE) imaging and chemical composition by energydispersive X-ray (EDX) spectroscopy.

The dense pellets were cut into bar-shaped and disc-shaped samples with a diamond wire saw for measurements of the thermoelectric properties. High-temperature electrical resistivity and thermopower were measured with an Ulvac-Riko ZEM-3 commercial apparatus in the temperature range $300-700 \mathrm{~K}$. In this temperature range, the thermal conductivity was calculated according to the relation $\kappa=\alpha c_{p} D$. The thermal diffusivity $\alpha$ was measured on disc-shaped samples by the laser flash technique (Netzsch LFA 427). The specific heat $c_{p}$ was estimated by the Dulong-Petit law, while the density $D$ was measured at $300 \mathrm{~K}$. The overall experimental uncertainty in $Z T$ is estimated to be $17 \%$. [30] The electrical resistivity, thermopower and thermal conductivity were measured at low temperatures $(5-$ $300 \mathrm{~K}$ ) using a custom made apparatus for the $\mathrm{Mg}$-substituted samples and a physical property measurement system (PPMS, Quantum Design) for the ternary tetrahedrite. Both systems employ the four-point electric and thermal transport method. 


\section{Results and Discussion}

PXRD patterns of the samples sintered by SPS are shown in Fig. 1a. These results confirm that the samples are composed mainly of the targeted tetrahedrite phase together with a small amount of secondary phases. These were identified as $\mathrm{Cu}_{3} \mathrm{SbS}_{4}$ and $\mathrm{CuSbS}_{2}$ in all the samples and a copper-rich tetrahedrite phase in the $x=0.5$ sample. Note that the $\mathrm{Cu}_{3} \mathrm{SbS}_{4}$ phase is usually observed in polycrystalline ternary $\mathrm{Cu}_{12} \mathrm{Sb}_{4} \mathrm{~S}_{13}$, if it were to be prepared by ball-milling or by powder metallurgy. [31, 32] The fraction of this impurity phase $(4,3$ and $1 \mathrm{wt} . \%$ for the $x=0.5,1.0$, and 1.5 samples, respectively) is found to scale with the $\mathrm{Mg}$ content with an increase in the $\mathrm{Mg}$ content resulting in a lower amount of $\mathrm{Cu}_{3} \mathrm{SbS}_{4}$ present in the sample. The weight fraction of the other phases is around $2 \%$ as determined from Rietveld refinements. The inset in Fig. 1a indicates that the reflections shift towards a lower angle as $x$ increases, which confirms that $\mathrm{Mg}$ has been successfully introduced into the tetrahedrite unit cell. Rietveld refinements against the PXRD patterns show evidence that the lattice parameter $a$ increases linearly with the nominal Mg content up to $x=1.5$ (see Fig. $1 \mathrm{~b}$ ) according to the relation $a=10.324+0.051 x \AA$. As we shall see below, the nominal value of $x$ is approximately twice as high as the actual $\mathrm{Mg}$ content in the tetrahedrite phase. Thus, $a$ increases approximately by $0.1 \AA$ per $\mathrm{Mg}$ atom per formula unit. This value is larger than what could be expected based solely on Shannon's ionic radius of $\mathrm{Mg}$ [33] which is comparable to other $d$-block elements. The value estimated for $\mathrm{Mg}$ is closer to $0.1 \AA$ per atom which is equivalent to substitutions by large atoms such as $\mathrm{Hg}$ [34] and $\mathrm{Cd}$ [21].

BSE images collected on the two end-member samples of this series, $x=0.5$ and $x=$ 1.5, are shown in Fig. 2. Both samples are composed mostly of the tetrahedrite phase in agreement with the PXRD analysis. According to EDX, this phase contains approximately one half of the nominal concentration of $\mathrm{Mg}$ atoms. The other half is found to form inclusions 
of the electrically insulating binary $\mathrm{MgS}$ also visible in the BSE images. The $\mathrm{Cu}_{3} \mathrm{SbS}_{4}$ and $\mathrm{CuSbS}_{2}$ phases observed in the PXRD patterns can also be identified. According to EDX, neither of these two phases contains $\mathrm{Mg}$ atoms.

The thermoelectric properties measured between 5 and $673 \mathrm{~K}$ are shown in Fig. 3. The data measured on the ternary $\mathrm{Cu}_{12} \mathrm{Sb}_{4} \mathrm{~S}_{13}$ are consistent with those reported by Suekuni et al. [3] In particular, the metal-to-insulator transition that sets in near $85 \mathrm{~K}$, leaving signatures in all transport coefficients, can be clearly seen. In addition, these measurements show hysteretic behavior above $200 \mathrm{~K}$ when the measurements are performed upon cooling and warming whose exact origin remains so far elusive. As shown in Fig. 3a, both features are still observable in the $x=0.5$ sample, although the steep rise in the electrical resistivity values below the metal-to-insulator transition is strongly lessened. The fact that this transition survives partial substitution is in line with recent results obtained on As-substituted samples, revealing that this transition is suppressed upon substitution smoothly rather than abruptly. [15] Intriguingly, the hysteretic behavior observed between 200 and $300 \mathrm{~K}$ is more pronounced than in the ternary compound. This change might hint towards an impuritytriggered decomposition since this sample contains a higher amount of secondary phase $\left(\mathrm{Cu}_{3} \mathrm{SbS}_{4}\right)$ compared to the ternary sample. Upon further increasing the $\mathrm{Mg}$ content to $x=1.0$ and 1.5, these two features are fully suppressed, leaving a steep rise in $\rho$ below $100 \mathrm{~K}$ characteristic of thermally-activated electrical properties. Above this temperature, the $\rho$ values smoothly decrease with increasing temperatures up to $300 \mathrm{~K}$, above which they remain nearly constant (see inset of Fig. 3a).

Above $300 \mathrm{~K}$, the $\rho$ values increase with increasing $\mathrm{Mg}$ content. The thermopower (Fig. 3b) follows a similar trend with $x$, with the highest measured value of $170 \mu \mathrm{V}$ K-1 achieved at $673 \mathrm{~K}$ in the $x=1.5$ sample. This behavior is consistent with an increase in the semiconducting character as $x$ increases, as observed for other partial substitutions on the $\mathrm{Cu}$ 
or $\mathrm{Sb}$ site. Substituting $\mathrm{Mg}$ for $\mathrm{Cu}$ therefore has a similar influence on the electronic band structure, a fact further supported by theoretical calculations [35]. $\mathrm{Mg}_{2+}$ progressively fills the two holes per formula unit present in the valence bands of $\mathrm{Cu}_{12} \mathrm{Sb}_{4} \mathrm{~S}_{13}$, reducing the carrier concentration and thereby resulting in a concomitant increase in the electrical resistivity and thermopower values. The magnitude of this effect is comparable to other substituents $[22,36]$ and further supports the fact that $\mathrm{Mg}$ is an effective doping species in the $\mathrm{Cu}_{12} \mathrm{Sb}_{4} \mathrm{~S}_{13}$ tetrahedrite.

The metal-to-insulator transition in the $x=0.0$ sample as well as the hysteretic behavior observed in the $x=0.0$ and $x=0.5$ samples also have a profound influence on the total thermal conductivity shown in Fig. $3 \mathrm{c}$ as a function of temperature. Indeed, upon cooling from 300 to $100 \mathrm{~K}$, the $x=0.0$ sample shows a dip near $200 \mathrm{~K}$ in addition to a continuous decrease. A second dip is observed near $85 \mathrm{~K}$ which closely corresponds to the metal-toinsulator transition accompanied by a distortion of the cubic unit cell. [37] The introduction of a small amount of $\mathrm{Mg}$ significantly enhances the first anomaly with a rather abrupt decrease between 300 and $200 \mathrm{~K}$ from 1.1 to $0.55 \mathrm{~W} \mathrm{~m}-1 \mathrm{~K}-1$, respectively. This stronger decrease, which corresponds to the temperature range where the hysteretic behavior is observed in the electrical resistivity, is mainly due to the higher $\rho$ values measured in this sample compared to the ternary compound. This leads to a significant decrease in the electronic contribution which drops well below $0.1 \mathrm{~W} \mathrm{m-1} \mathrm{K-1.} \mathrm{The} \mathrm{second} \mathrm{anomaly} \mathrm{near} 85 \mathrm{~K}$ is no longer visible, which is in agreement with the general fact that a partial substitution on the $\mathrm{Cu}, \mathrm{Sb}$ or $\mathrm{S}$ site tends to suppress the low-temperature metal-to-insulator transition. Upon further increasing the $\mathrm{Mg}$ content to $x=1.0$ and eventually to $x=1.5$, the conventional, glass-like temperature dependence widely observed in tetrahedrites is recovered. At high temperatures, the total thermal conductivity decreases with increasing $\mathrm{Mg}$ content. This effect is also due to the increase in the electrical resistivity values which leads to a decrease of the electronic 
contribution to the thermal conductivity. The minimum thermal conductivity value of $0.8 \mathrm{~W} \mathrm{~m}-1 \mathrm{~K}-1$ has been measured at $673 \mathrm{~K}$ for the $x=1.5$ sample, a value typically observed in substituted tetrahedrites.

Finally, Fig. 3d shows the temperature dependence of the dimensionless thermoelectric figure of merit $Z T$. The decrease in the total thermal conductivity is counterbalanced by the decrease in the power factor due to a significant rise in the electrical resistivity values upon substituting $\mathrm{Mg}$ for $\mathrm{Cu}$. This substitution therefore leaves the $Z T$ values unchanged with respect to the ternary sample. A peak $Z T$ value of 0.55 at $673 \mathrm{~K}$ is equivalent for all the samples.

\section{Conclusion}

We successfully synthesized a series of Mg-substituted tetrahedrite samples $\mathrm{Cu}_{12-x} \mathrm{Mg}_{x} \mathrm{Sb}_{4} \mathrm{~S}_{13}$ and confirmed the incorporation of Mg into the unit cell from EDX and PXRD analyses. To the best of our knowledge, an s-block element has not been considered before in the crystal structure of tetrahedrites. As all other elements of the $d$ - and $p$-block studied so far, Mg was found to drive the metallic ternary $\mathrm{Cu}_{12} \mathrm{Sb}_{4} \mathrm{~S}_{13}$ closer to a semiconducting state. This behavior has been experimentally confirmed by a concomitant increase in the electrical resistivity and thermopower with increasing $x$. In agreement with prior studies on tetrahedrites, the thermal conductivity of all samples is very low, reaching $0.8 \mathrm{~W} \mathrm{m-1} \mathrm{K}-1$ at $673 \mathrm{~K}$ in the $x=1.5$ sample. Nevertheless, the combination of these effects leaves the dimensionless thermoelectric figure of merit $Z T$ mostly unaffected because of the high electrical resistivity values. As a result, a peak $Z T$ value of 0.55 at $673 \mathrm{~K}$ was found to be equivalent in all three $\mathrm{Mg}$-containing samples and in pristine $\mathrm{Cu}_{12} \mathrm{Sb}_{4} \mathrm{~S}_{13}$. This study demonstrates that other $s$-block elements may be worth considering to determine whether they can be beneficial for optimizing the thermoelectric performance of tetrahedrites. 


\section{Acknowledgements}

This work was performed with the financial support of the Czech Science Foundation (project

No. 14-36566G and 18-12761S), the Operational Programme Research, Development and Education (Center of Advanced Applied Sciences project No. CZ.02.1.01/0.0/0.0/16_019/0000778) and the Grant Agency of the Czech Technical University in Prague (grant No. SGS16/245/OHK4/3T/14). 


\section{References}

[1] H.J. Goldsmid, Thermoelectric Refrigeration (Temple University Press, London, 1964).

[2] D.M. Rowe, Thermoelectrics and Its Energy Harvesting (CRC Press, Boca Raton, 2012).

[3] K. Suekuni, K. Tsuruta, T. Ariga, and M. Koyano, Appl. Phys. Express 5, 051201 (2012).

[4] N.E. Johnson, J.R. Craig, and J.D. Rimstidt, Can. Mineral. 24, 385 (1986).

[5] P. Levinsky, J.-B. Vaney, C. Candolfi, A. Dauscher. B. Lenoir, and J. Hejtmánek, J. Electron. Mater. 45, 1351 (2016).

[6] X. Lu, D.T. Morelli, Y. Xia, F. Zhou, V. Ozolins, H. Chi, X. Zhou, and Ctirad Uher, Adv. Energy Mater. 3, 342 (2013).

[7] R. Chetty, A. Bali, M.H. Naik, G. Rogl, P. Rogl, M. Jain, S. Suwas, and R.C. Mallik, Acta Mater. 100, 266 (2015).

[8] R. Chetty, A. Bali, and R.C. Mallik, J. Mater. Chem. C 3, 12364 (2015).

[9] K. Suekuni and T. Takabatake, APL Mater. 4, 104503 (2016).

[10] E. Lara-Curzio, A.F. May, O. Delaire, M.A. McGuire, X. Lu, C.-Y. Liu, E.D. Case, and D.T. Morelli, J. Appl. Phys. 115, 193515 (2014).

[11] Y. Bouyrie, C. Candolfi, S. Pailhès, M. M. Koza, B. Malaman, A. Dauscher, J. Tobola, O. Boisron, L. Saviot, and B. Lenoir, Phys. Chem. Chem. Phys. 17, 19751 (2015).

[12] W. Lai, Y. Wang, D.T. Morelli, and X. Lu, Adv. Funct. Mater. 25, 3648 (2015).

[13] X. Lu, D.T. Morelli, Y. Wang, W. Lai, Y. Xia, and V. Ozolins, Chem. Mater. 28, 1781 (2016).

[14] X. Lu, W. Yao, G. Wang, X. Zhou, D. Morelli, Y. Zhang, H. Chi, S. Hui, and C. Uher, RSC Adv. 7,12719 
(2017).

[15] H.I. Tanaka, K. Suekuni, K. Umeo, T. Nagasaki, H. Sato, G. Kutluk, E. Nishibori, H. Kasai, and T. Takabatake, J. Phys. Soc. Jpn. 85, 014703 (2016).

[16] Y. Bouyrie, C. Candolfi, V. Ohorodniichuk, B. Malaman, A. Dauscher, J. Tobola, and B. Lenoir, J. Mater. Chem. C 3, 10476 (2015).

[17] Y. Bouyrie, C. Candolfi, A. Dauscher, B. Malaman, and B. Lenoir, Chem. Mater. 27, 8354 (2015).

[18] D.S.P. Kumar, R. Chetty, O.E. Femi, K. Chattopadhyay, P. Malar, and R. C. Mallik, J. Electron. Mater. 46, 2616 (2017).

[19] K. Suekuni, K. Tsuruta, M. Kunii, H. Nishiate, E. Nishibori, S. Maki, M. Ohta, A. Yamamoto, and M. Koyano, J. Appl. Phys. 113, 043712 (2013).

[20] T. Barbier, P. Lemoine, S. Gascoin, O.I. Lebedev, A. Kaltzoglou, P. Vaqueiro, A.V. Powell, R.I. Smith, and E. Guilmeau, J. Alloys Compd. 634, 253 (2015).

[21] D.S.P. Kumar, R. Chetty, P. Rogl, G. Rogl, E. Bauer, P. Malar, and R.C. Mallik, Intermetallics 78, 21 (2016)

[22] Y. Kosaka, K. Suekuni, K. Hashikuni, Y. Bouyrie, M. Ohta, and T. Takabatake, Phys. Chem. Chem. Phys. 19, 8874 (2017).

[23] X. Lu and D.T. Morelli, Phys. Chem. Chem. Phys. 15, 5762 (2013).

[24] X. Lu, D.T. Morelli, Y. Xia, and V. Ozolins, Chem. Mater. 27, 408 (2015).

[25] Y. Bouyrie, C. Candolfi, J. B. Vaney, A. Dauscher, and B. Lenoir, J. Electron. Mater. 45, 1601 (2016).

[26] Y. Bouyrie, S. Sassi, C. Candolfi, J.-B. Vaney, A. Dauscher, and B. Lenoir, Dalton T. 45, 7294 (2016).

[27] A.P. Gonçalves, E.B. Lopes, B. Villeroy, J. Monnier, C. Godart, and B. Lenoir, RSC Adv. 6, 102359 (2016). 
[28] A.P. Gonçalves, E.B. Lopes, M.F. Montemor, J. Monnier, and B. Lenoir, J. Electron. Mater. 47, 2880 (2018).

[29] J. Rodriguez-Carvajal, Physica B 192, 55 (1993).

[30] E. Alleno, D. Bérardan, C. Byl, C. Candolfi, R. Daou, R. Decourt, E. Guilmeau, S. Hébert, J. Hejtmanek, B. Lenoir, P. Masschelein, V. Ohorodniichuk, M. Pollet, S. Populoh, D. Ravot, O. Rouleau, and M. Soulier, Rev. Sci. Instrum. 86, 011301 (2015).

[31] P. Vaqueiro, G. Guélou, A. Kaltzoglou, R.I. Smith, T. Barbier, E. Guilmeau, and A.V. Powell, Chem. Mater. 29, 4080 (2017).

[32] F.-H. Sun, C.-F. Wu, Z. Li, Y. Pan, Asfandiyar, J. Dong, and J.-F. Li, RSC Adv. 7, 18909 (2017).

[33] R.D. Shannon, Acta Crystallogr. A 32, 75 (1976).

[34] E. Makovicky and S. Karup-Mфller, Neues Jb. Miner. Abh. 179, 73 (2003).

[35] K. Knižek, P.Levinský, and J. Hejtmánek, J. Electron. Mater. (2019) doi:10.1007/s11664-019-06960-x.

[36] R. Chetty, D.S.P. Kumar, G. Rogl, P. Rogl, E. Bauer, H. Michor, S. Suwas, S. Puchegger, G. Giester, and R.C. Mallik, Phys. Chem. Chem. Phys. 17, 1716 (2014).

[37] D.I. Nasonova, V.Y. Verchenko, A.A. Tsirlin, and A.V. Shevelkov, Chem. Mater. 28, 6621 (2016).

\section{List of Figures}

Fig. 1: (a) PXRD patterns of the sintered samples. The patterns have been shifted vertically for sake of clarity. All the main peaks can be indexed to the tetrahedrite phase. The impurity phases $\mathrm{Cu}_{3} \mathrm{SbS}_{4}$, marked by v, and $\mathrm{CuSbS}_{2}$, marked by |, are visible in these patterns. The inset highlights the shift of the (222) main diffraction peak as the Mg content increases. (b) Dependence of the cell parameter $a$ on nominal Mg content $x$. 
Fig. 2: BSE images of polished surfaces of the SPS sintered samples with (a) $x=0.5$ and (b) $x$ $=1.5$. The samples are mostly composed of the tetrahedrite phase which contains Mg. Darker areas indicate $\mathrm{Cu}_{3} \mathrm{SbS}_{4}$, white spots indicate $\mathrm{CuSbS}_{2}$, and black spots indicate $\mathrm{MgS}$.

Fig. 3: Temperature dependence of the thermoelectric properties of the studied samples: (a) electrical resistivity, (b) Seebeck coefficient, (c) thermal conductivity and (d) $Z T$. 
(a)

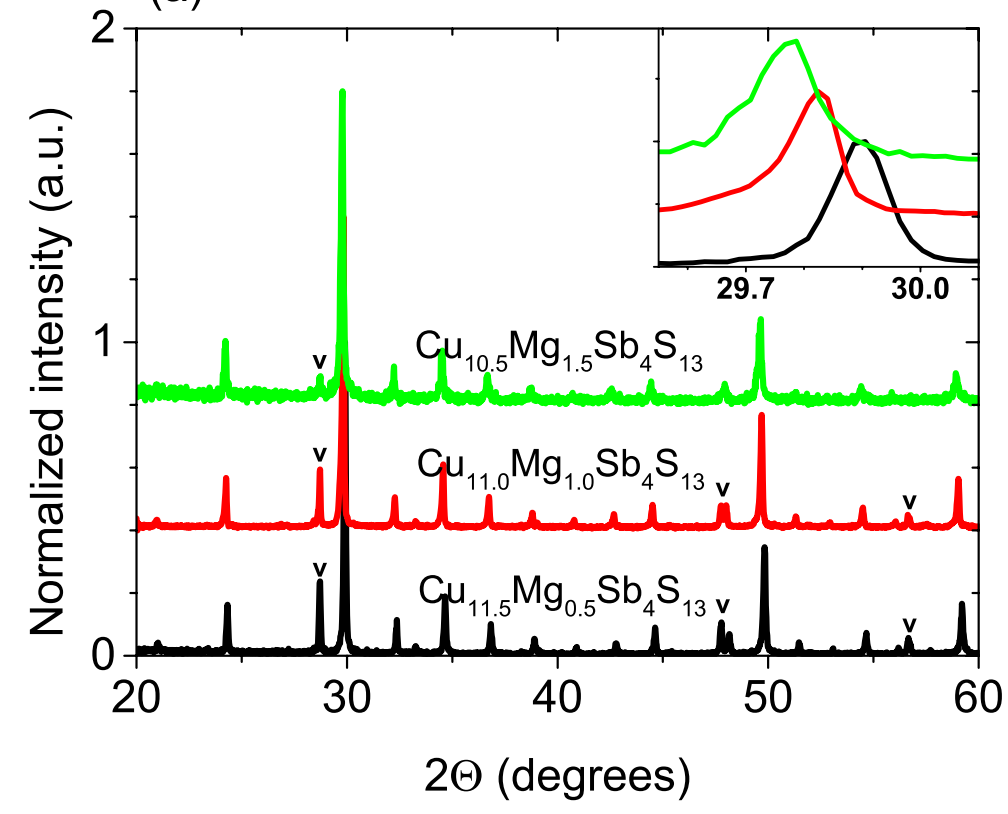

(b)

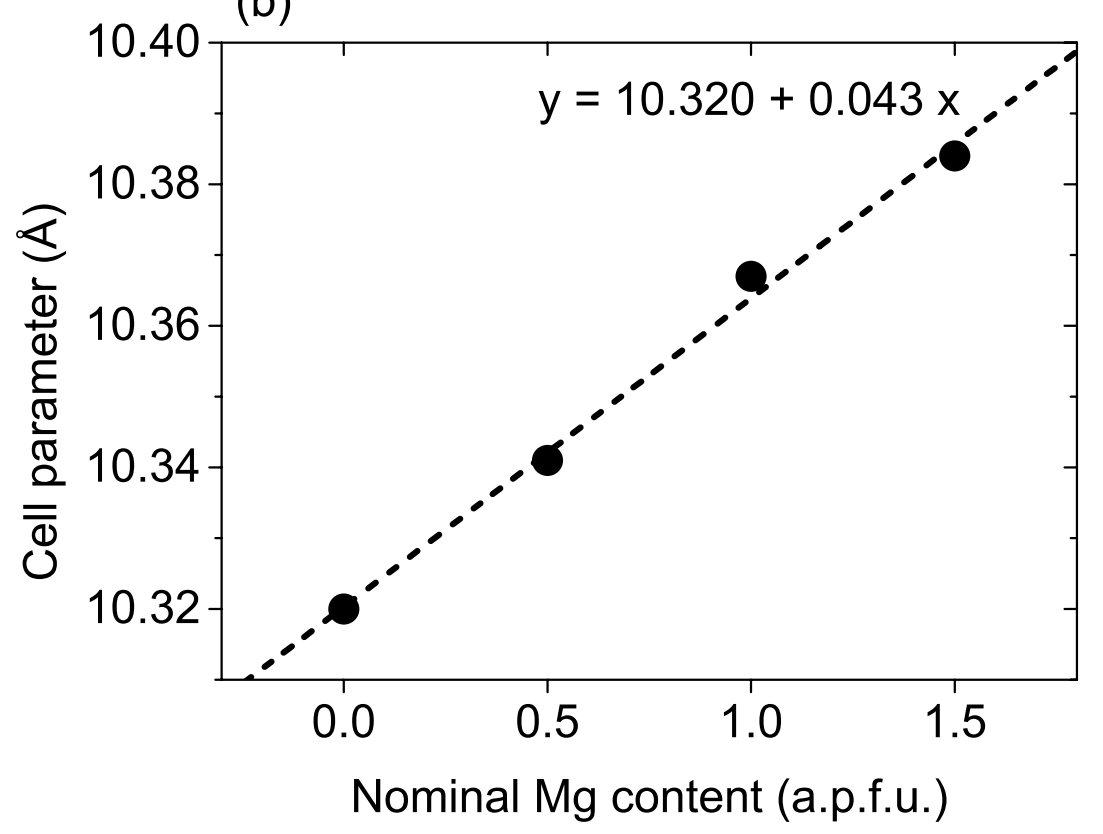

Figure 1 

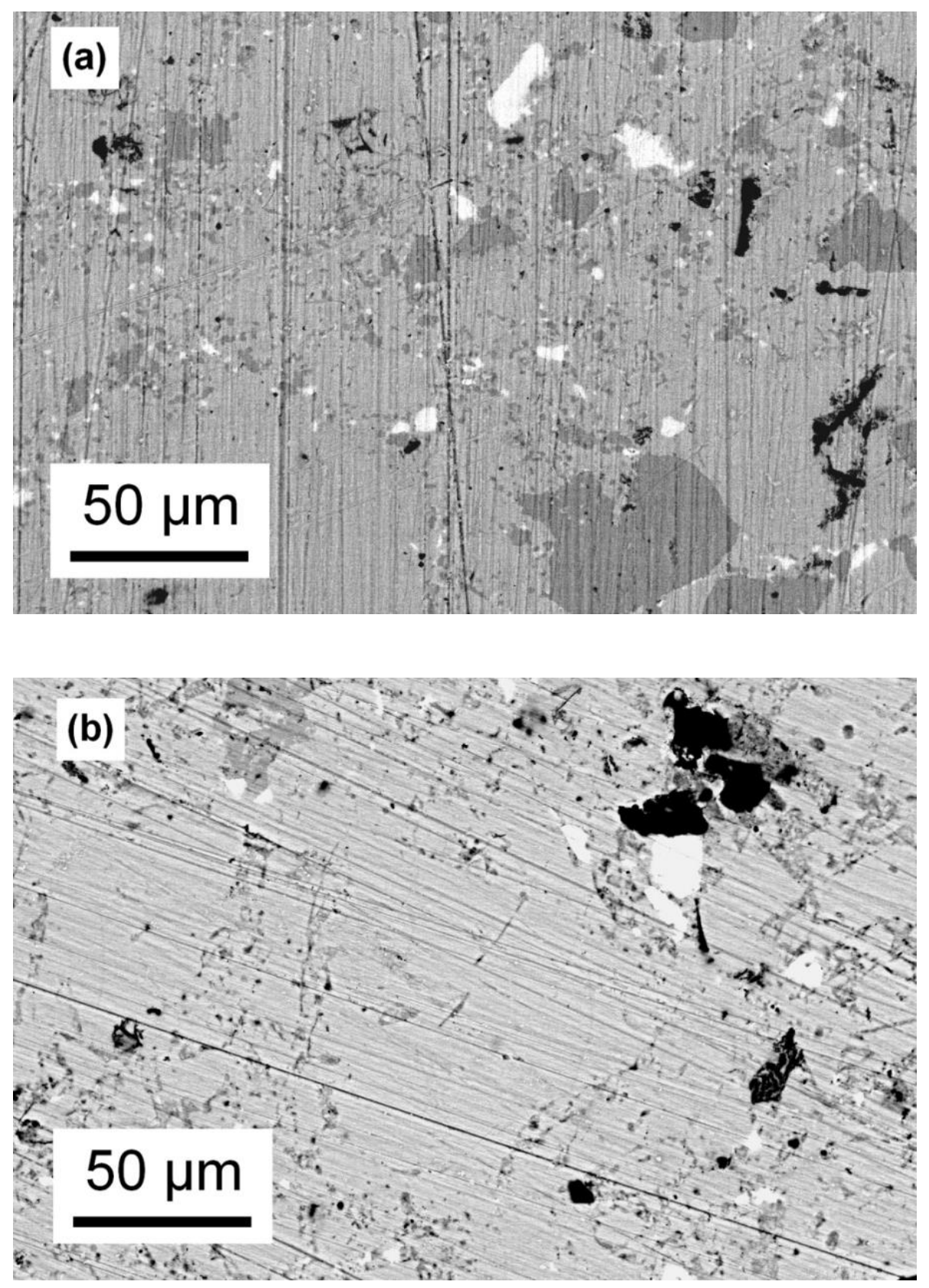

Figure 2 

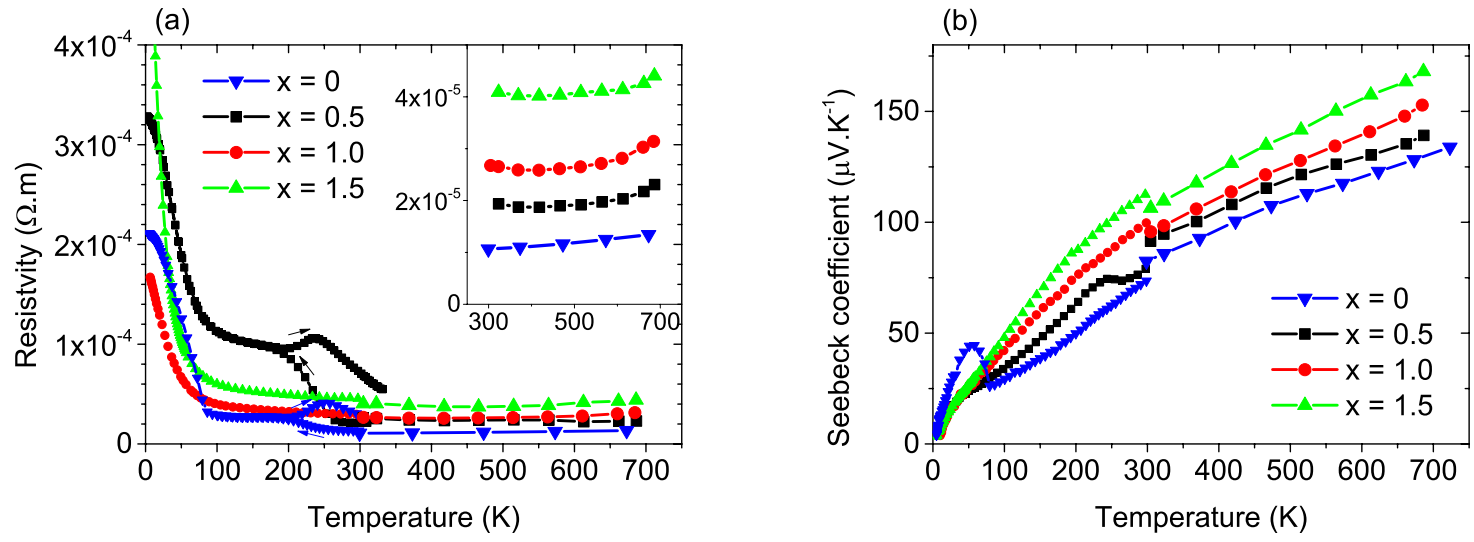

(c)
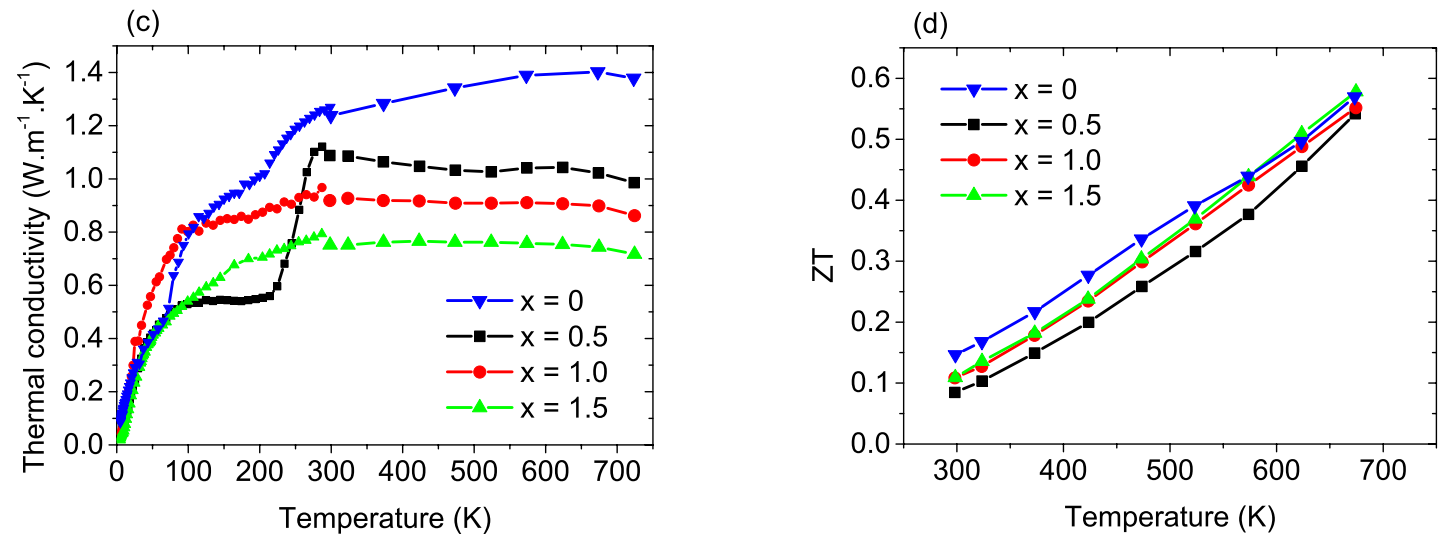

Figure 3 